\title{
Quantitative Photocatalytic Activity under Visible Light with $\mathrm{Mn}-\mathrm{ACF} / \mathrm{TiO}_{2}$
}

\author{
Shu Ye, Hyun-il Kim, and Won-Chun $\mathrm{Oh}^{\dagger}$ \\ Department of Advanced Materials Science \& Engineering, Hanseo University, Seosan 31962, Korea
}

(Received March 28, 2016; Revised April 8, 2016; Accepted April 16, 2016)

\begin{abstract}
Manganese and $\mathrm{TiO}_{2}$ grown on Activated Carbon Fiber (ACF) was synthesized by hydrothermal method. The prepared composites were characterized by X-ray diffraction (XRD) and scanning electron microscopy (SEM) with energy dispersive X-ray (EDX). The catalytic behavior was investigated through the decomposition of methylene blue (MB) and methyl orange (MO) as standard dyes under visible light. The degradation performance of the degraded standard dye solutions was determined by UV-Vis spectrophotometry. This enhanced photocatalytic activity arises from the positive synergetic effect among the $\mathrm{Mn}, \mathrm{TiO}_{2}$ and $\mathrm{ACF}$ in this heterogeneous photocatalyst. The process contributes to the release of abundant photocatalytic sites of $\mathrm{Mn}^{2}$ and $\mathrm{TiO}_{2}$ and improves the photocatalytic efficiency. The excellent adsorption and photocatalytic effect with the explanation of the synergetic mechanism are very useful not only for fundamental research but also for potential practical applications.
\end{abstract}

Key words : $\mathrm{TiO}_{2}$ ACF, Hydrothermal, XRD, Visible light

\section{Introduction}

$\mathrm{T}$ itanium dioxide $\left(\mathrm{TiO}_{2}\right)$ has advantages over other photocatalysts such as high activity, good stability, low cost and nontoxicity to humans. However, the main shortcoming of $\mathrm{TiO}_{2}$ is its relatively large band-gap (anatase: $3.2 \mathrm{eV}$ ). As a consequence, $\mathrm{TiO}_{2}$ shows photocatalytic activity only in the near ultraviolet region and can get only a small fraction of incident solar irradiation. ${ }^{1-4)}$ Therefore, modifying $\mathrm{TiO}_{2}$ photocatalysts to enhance light absorption and photocatalytic activity under visible light irradiation has become the main research direction in recent years.

In the last two decades, Activated Carbon Fiber (ACF), widely used as an effective adsorbent in treating polluted water and gas, has been introduced as a support for $\mathrm{TiO}_{2}$ photocatalysts in several studies. ${ }^{5-8)}$ ACFs are one kind of highly microporous carbon material, having a higher surface area, larger pore volume and a more uniform micropore size distribution than those characteristics of granular activated carbon. ${ }^{9-11)}$ However, so far there have been only a few reports that have studied preparation methods for and applications of $\mathrm{ACF} / \mathrm{TiO}_{2}$ composites.

Doping metal ion to $\mathrm{TiO}_{2}$, which could introduce defects in the lattice or change the crystallinity, would extend the photocatalytic functionality into the visible light range and lead to the more efficient separation of photo electrons and holes as well. Manganese oxides have also been used as adsorbents for dye decomposition. However, the use of manga-

${ }^{\dagger}$ Corresponding author: Won-Chun Oh

E-mail : wc_oh@hanseo.ac.kr

Tel : +82-41-660-1337 Fax : +82-41-688-3352 nese oxide modified ACF for dye decomposition has not been reported. In the present study, manganese-modified $\mathrm{TiO}_{2}$ located on activated carbon fiber $\left(\mathrm{Mn}-\mathrm{ACF} / \mathrm{TiO}_{2}\right)$ was prepared; the degradation performance of the MB solution was determined by UV-Vis spectrophotometry. ${ }^{12-16)}$

In this study, we have focused on characterization of the obtained $\mathrm{Mn}-\mathrm{ACF} / \mathrm{TiO}_{2}$ composite in porous $\mathrm{ACF}$ and the formation of $\mathrm{TiO}_{2}$ derived from titanium n-butoxide (TNB). The conversion of TNB to $\mathrm{TiO}_{2}$ during heat treatment is important for the preparation of $\mathrm{Mn}-\mathrm{ACF} / \mathrm{TiO}_{2}$ composites. The as-prepared $\mathrm{Mn}-\mathrm{ACF} / \mathrm{TiO}_{2}$ catalysts were characterized using XRD, EDX and SEM. The catalytic behavior was investigated through the decomposition of standard dyes (MB, MO). The degradation performance of degraded MB and MO solutions was determined by UV-Vis spectrophotometry.

\section{Experimental Procedure}

\subsection{Materials}

Self-made ACFs used as precursor fiber material were prepared from commercial PAN based carbon fibers (T-300 Amoco, USA). The carbon fibers were activated by steam diluted with nitrogen in a cylindrical alumina tube at a temperature of $1073 \mathrm{~K}$ for $30 \mathrm{~min}$. These ACFs were washed with deionized water and dried for $24 \mathrm{~h}$ at ambient temperature. For the treatment of Mn sources to ACF matrix, $\mathrm{MnCl}_{2}$ was obtained from Duksan Pure Chemical Co. (99+\%, ACS reagent, Korea) and used as received. In the process of metal treatment, $2 \mathrm{~g}$ of ACF was dipped into $100 \mathrm{~mL}$ of 1.0, 2.0 and $3.0 \mathrm{M} \mathrm{MnCl}_{2}$ solutions and stirred for $24 \mathrm{~h}$ at room temperature. The samples obtained were then dried at $383 \mathrm{~K}$ for $48 \mathrm{~h}$ in an air atmosphere. For the TNB treatment 
Table 1. Nomenclature of Pristine ACF and $\mathrm{Mn}-\mathrm{ACF} / \mathrm{TiO}_{2}$ Composites Prepared with Different Concentrations of $\mathrm{MnCl}_{2}$ and $\mathrm{ACFs}$

\begin{tabular}{cccc}
\hline $\mathrm{ACF}$ & $\mathrm{MnCl}_{2}$ & $\mathrm{TNB}$ & Sample name \\
\hline $2 \mathrm{~g}$ & $1.0 \mathrm{M}$ & $4 \mathrm{~mL}$ & $\mathrm{Mn}-\mathrm{ACF} / \mathrm{TiO}_{2}-1$ \\
$2 \mathrm{~g}$ & $2.0 \mathrm{M}$ & $4 \mathrm{~mL}$ & $\mathrm{Mn}-\mathrm{ACF} / \mathrm{TiO}_{2}-2$ \\
$2 \mathrm{~g}$ & $3.0 \mathrm{M}$ & $4 \mathrm{~mL}$ & $\mathrm{Mn}-\mathrm{ACF} / \mathrm{TiO}_{2}-3$ \\
\hline
\end{tabular}

of $\mathrm{Mn}^{-\mathrm{TiO}_{2}}$, we prepared Mn-containing ACF slurry solutions with pristine concentrations of $4 \mathrm{~mL}$ of titanium nbutoxide (TNB, $\mathrm{C}_{16} \mathrm{H}_{36} \mathrm{O}_{4} \mathrm{Ti}$, Acros Organics, USA) for the preparation of the $\mathrm{Mn}-\mathrm{ACF} / \mathrm{TiO}_{2}$ composites. Then, the solvent in the mixtures was vaporized at $343 \mathrm{~K}$ for $1 \mathrm{~h}$. The powder mixtures of TNB and Mn-ACF were heated at $973 \mathrm{~K}$ for $1 \mathrm{~h}$. The simple preparation method and nomenclature of the prepared samples are listed in Table 1.

\subsection{Characterization of the samples}

XRD (Shimatz XD-D1, Japan) analysis using Cu Ka radiation was performed to assess the crystallinity and phase transition of the synthesized catalysts. An elemental analyzer was used to obtain EDX spectra for the prepared composites. For the measurement of the photo-degradation effects, UV/vis spectra for the aqueous solutions decomposed with $\mathrm{Mn}-\mathrm{ACF} / \mathrm{TiO}_{2}$ composites were obtained using a scanning UV-Vis spectrophotometer (Neosys-2000) equipped with an integrating sphere assembly. The BET surface area of the photocatalysts was determined by nitrogen adsorption at $196{ }^{\circ} \mathrm{C}$ using a BET analyzer (Monosorb, USA). SEM (JSM-5200 JOEL, Japan) was used to observe the surface state and structure of the $\mathrm{Mn}-\mathrm{ACF} / \mathrm{TiO}_{2}$ composites.

\subsection{Photocatalytic studies}

The photocatalytic activity of the as-prepared Mn-ACF/ $\mathrm{TiO}_{2}$ nanocomposites was evaluated by the degradation of MB under visible light. An LED lamp (8W, $\lambda>420 \mathrm{~nm}$, KLD-08L LED lamp) served as the simulated visible light source. In each run, $10 \mathrm{mg}$ of the $\mathrm{Mn}-\mathrm{ACF} / \mathrm{TiO}_{2}$ catalytic sample was added to a $50 \mathrm{ml}$ solution of $\mathrm{MB}\left(0.1 \mathrm{mg} \mathrm{ml}^{-1}\right)$. To obtain adsorption-desorption equilibrium, the solution was kept in the dark for $2 \mathrm{~h}$. Before the LED lamp was switched on, each sample was collected from the solution and kept in a centrifuge at $10000 \mathrm{rpm}$ for the removal of solid material. Afterwards, the LED lamp was switched on and samples were collected periodically. At given time intervals, the collected samples were immediately centrifuged for 10 minutes to remove solid material for further analysis. Each photocatalyst composite was irradiated for 150 minutes to compare its catalytic efficiencies. ${ }^{17-20)}$

\section{Results and Discussion}

\subsection{Characterization}

XRD patterns were used to identify the crystallite phases of the $\mathrm{Mn}-\mathrm{ACF} / \mathrm{TiO}_{2}$ nanocomposites with varying $\mathrm{ACF}$ con- tents. Fig. 1 compares the XRD patterns of the Mn-ACF/ $\mathrm{TiO}_{2}$ nanocomposites. The results of XRD for all composites show no diffraction peaks for the carbon matrix as corresponding to the inorganic amorphous phase. The Mn-ACF/ $\mathrm{TiO}_{2}$ composites with different compositions exhibit characteristic (101), (004), (200), (105), (211) and (220) reflections that correspond to the anatase crystal phase. By applying the Scherrer equation to the strongest (101) peak, the nanocrystal sizes of the $\mathrm{Mn}-\mathrm{ACF} / \mathrm{TiO}_{2}-1, \mathrm{Mn}-\mathrm{ACF} / \mathrm{TiO}_{2}-2$ and $\mathrm{Mn}-\mathrm{ACF} / \mathrm{TiO}_{2}-3$ are found to be $7-8 \mathrm{~nm}, 9$ - $10 \mathrm{~nm}$ and $10-$ $11 \mathrm{~nm}$, respectively. With increasing $\mathrm{Mn}$ concentration, the intensity of the peaks of all the lattice planes increases. The peak intensity of $\mathrm{Mn}-\mathrm{ACF} / \mathrm{TiO}_{2}-3$ is stronger than that of the others, indicating that high $\mathrm{Mn}^{2+}$ concentration helps to increase the particle size.

The EDX analysis data of the $\mathrm{Mn}-\mathrm{ACF} / \mathrm{TiO}_{2}$ composites are listed in Table 2 . These spectra show the main elements as $\mathrm{C}, \mathrm{O}$ and $\mathrm{Mn}$, with strong Ti peaks. Most of these samples were much richer in carbon and major oxygen than in any other elements. C, Mn and Ti were confirmed as componential elements in most of the $\mathrm{Mn}-\mathrm{ACF} / \mathrm{TiO}_{2}$ samples. These results show the spectra corresponding to almost all samples decreased in $\mathrm{C}$ elements and increased in $\mathrm{O}, \mathrm{Mn}$ and Ti elements. This means that special effects have been dedicated to the treatment of $\mathrm{Mn}$. This interest is based on the idea that $\mathrm{Mn}$ ions act as shallow charge traps or electron-hole recombination centers in the composite. ${ }^{21-23)}$

The BET surface areas of the samples are shown in Table 3. This value decreased from $1093.6 \mathrm{~m}^{2} / \mathrm{g}$ for $\mathrm{Mn}-\mathrm{ACF} / \mathrm{TiO}_{2}-1$ to $982.3 \mathrm{~m}^{2} / \mathrm{g}$ for $\mathrm{Mn}-\mathrm{ACF} / \mathrm{TiO}_{2}-3$. This was because $\mathrm{Mn}$ and

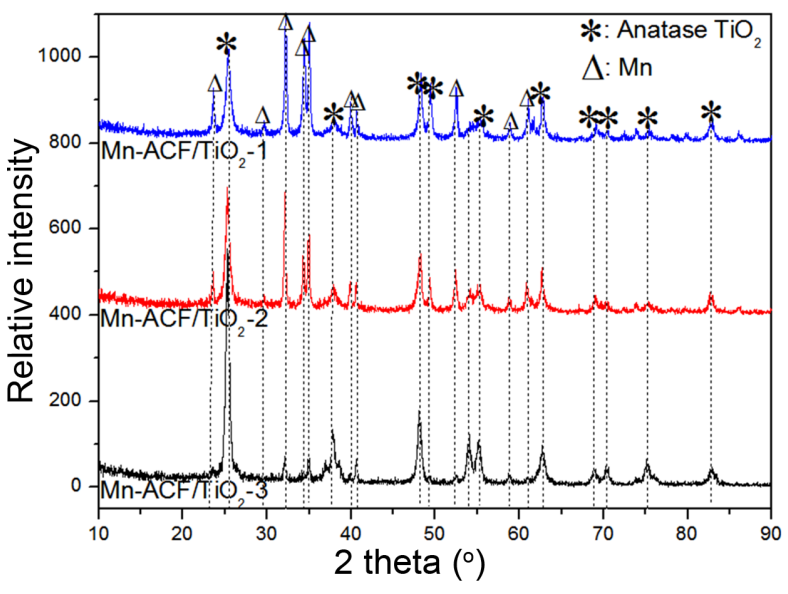

Fig. 1. XRD patterns of prepared samples.

Table 2. EDX Elemental Microanalysis of $\mathrm{Mn}-\mathrm{ACF} / \mathrm{TiO}_{2}$ Samples

\begin{tabular}{ccccc}
\hline Element (wt.\%) & $\mathrm{C}$ & $\mathrm{O}$ & $\mathrm{Ti}$ & $\mathrm{Mn}$ \\
\hline $\mathrm{Mn}-\mathrm{ACF} / \mathrm{TiO}_{2}-1$ & 51.63 & 28.35 & 18.9 & 1.12 \\
$\mathrm{Mn}-\mathrm{ACF} / \mathrm{TiO}_{2}-2$ & 48.57 & 28.24 & 21.5 & 1.69 \\
$\mathrm{Mn}-\mathrm{ACF} / \mathrm{TiO}_{2}-3$ & 45.41 & 30.14 & 22.3 & 2.15 \\
\hline
\end{tabular}


Table 3. BET Surface Area of As-Prepared Catalysts

\begin{tabular}{|c|c|c|c|c|c|}
\hline Sample & Surface Parameter & $\begin{array}{c}\mathrm{S}_{\mathrm{BET}} \\
\left(\mathrm{m}^{2} / \mathrm{g}\right)\end{array}$ & $\frac{\mathrm{V}_{\mathrm{m}}}{\left(\mathrm{cm}^{3}(\mathrm{STP}) / \mathrm{g}\right)}$ & $\begin{array}{l}\text { Total Pore Volume } \\
\left(\mathrm{cm}^{3} / \mathrm{g}\right)\end{array}$ & $\begin{array}{c}\text { Average Pore Diameter } \\
(\mathrm{nm})\end{array}$ \\
\hline & $\mathrm{Mn}-\mathrm{ACF} / \mathrm{TiO}_{2}-1$ & 1093.6 & 86.50 & 0.192 & 2.04 \\
\hline & $\mathrm{Mn}-\mathrm{ACF} / \mathrm{TiO}_{2}-2$ & 1009.3 & 66.75 & 0.140 & 2.11 \\
\hline & $\mathrm{Mn}-\mathrm{ACF} / \mathrm{TiO}_{2}-3$ & 982.30 & 73.33 & 0.181 & 2.28 \\
\hline
\end{tabular}
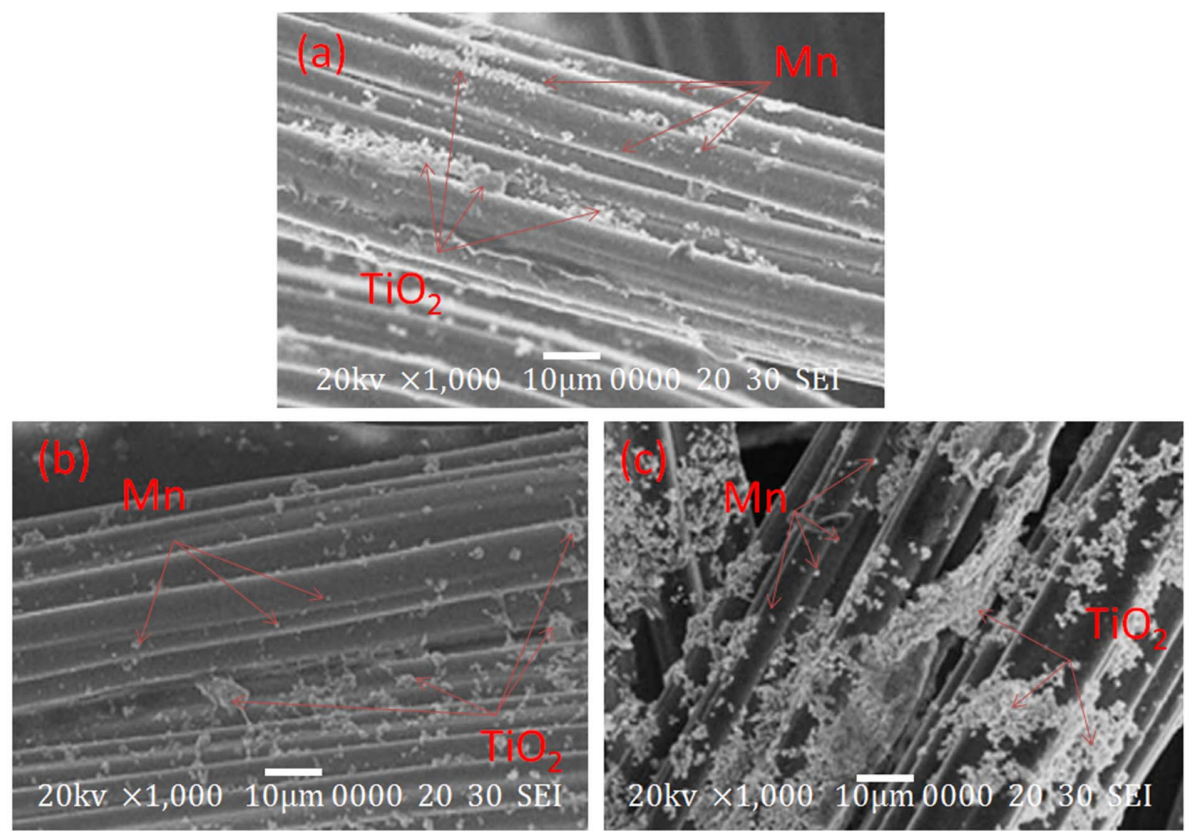

Fig. 2. SEM images of $\mathrm{Mn}-\mathrm{ACF} / \mathrm{TiO}_{2}-1$ (a), Mn-ACF/TiO ${ }_{2}-2$ (b) and $\mathrm{Mn}-\mathrm{ACF} / \mathrm{TiO}_{2}-3$ (c)

$\mathrm{TiO}_{2}$ nanoparticles were introduced into the pores of the $\mathrm{ACF}$, decreasing the BET surface area. $\mathrm{Mn}-\mathrm{ACF} / \mathrm{TiO}_{2}-1$ has the largest area. From the values, it is evident that the ACFs have good BET values that can affect the adsorption reaction time.

The SEM images of the $\mathrm{Mn}-\mathrm{ACF} / \mathrm{TiO}_{2}$ composites are shown in Fig. 2. It can be sen that the titanium complexes containing particles are evenly distributed in all types of the $\mathrm{Mn}-\mathrm{ACF} / \mathrm{TiO}_{2}$ composites. The average particle size, estimated from SEM observations, was not considerably large in the composites prepared from iron and titanium sources. Although the titanium complex particles on the carbon surfaces become pronounced and coarse, no iron complex particles were observed due to ionic size. The needle-like crystals on the surface of $\mathrm{Mn}-\mathrm{ACF} / \mathrm{TiO}_{2}$ should be manganese species. It was reported that there are some organic groups such as carboxyl $(-\mathrm{COOH})$ and hydroxyl $(-\mathrm{OH})$ groups on the surface of $\mathrm{ACF}{ }^{24-25)}$ which facilitate the adsorption of $\mathrm{Mn}^{2+}$ ions and $\mathrm{TiO}_{2}$ on the surface of ACF by electrostatic interaction.

\subsection{Novel photonic performance of dyes}

Figure 3 shows the MB degradation versus time using $\mathrm{Mn}-\mathrm{ACF} / \mathrm{TiO}_{2}-1, \mathrm{Mn}-\mathrm{ACF} / \mathrm{TiO}_{2}-2$ and $\mathrm{Mn}-\mathrm{ACF}_{2} / \mathrm{TiO}_{2}-3$ under visible light. The spectra for the $\mathrm{MB}$ solution after visible light irradiation showed relative degradation yields at different irradiation times. The dye concentration continuously decreased with a gentle slope; this was due to visible light irradiation. The concentration of $\mathrm{MB}$ was $5.0 \times$ $10^{-5} \mathrm{~mol} / \mathrm{L}$, and the absorbance for MB decreased with increasing visible light irradiation time. Moreover, the MB solution increasingly lost its color as the MB concentration continued to decrease. Two steps are involved in the photocatalytic decomposition of dyes: adsorption of dye molecules and their degradation. After adsorption in the dark for 120 min with magnetic stirring, the samples were irradiated for $120 \mathrm{~min}$ under visible light. In the adsorption step, Mn$\mathrm{ACF}_{\mathrm{TiO}}-1, \mathrm{Mn}-\mathrm{ACF} / \mathrm{TiO}_{2}-2$ and $\mathrm{Mn}-\mathrm{ACF} / \mathrm{TiO}_{2}-3$ composites showed different adsorption capacities, with Mn-ACF/ $\mathrm{TiO}_{2}-2$ having the highest adsorption capacity. In order to test the adsorption ability of the nanocomposites, the concentration changes of the MB solution were recorded and are shown in Fig. 4. It can be clearly seen that $30 \%$ of $\mathrm{MB}$ was degraded by the $\mathrm{Mn}-\mathrm{ACF}_{\mathrm{TiO}}-2$ nanocomposite. Adsorption of $\mathrm{MB}$ was slightly reduced by the incorporation of different amounts of $\mathrm{MnCl}_{2}$ to $\mathrm{TiO}_{2}$ in the composites. This is a possible reason for the light transparent increase with the decrease of $\mathrm{MB}$ concentration by photocatalytic combination effects. After that, the $\mathrm{Mn}-\mathrm{ACF} / \mathrm{TiO}_{2}-2$ samples were tried to degrade MO solution under visible light irradi- 

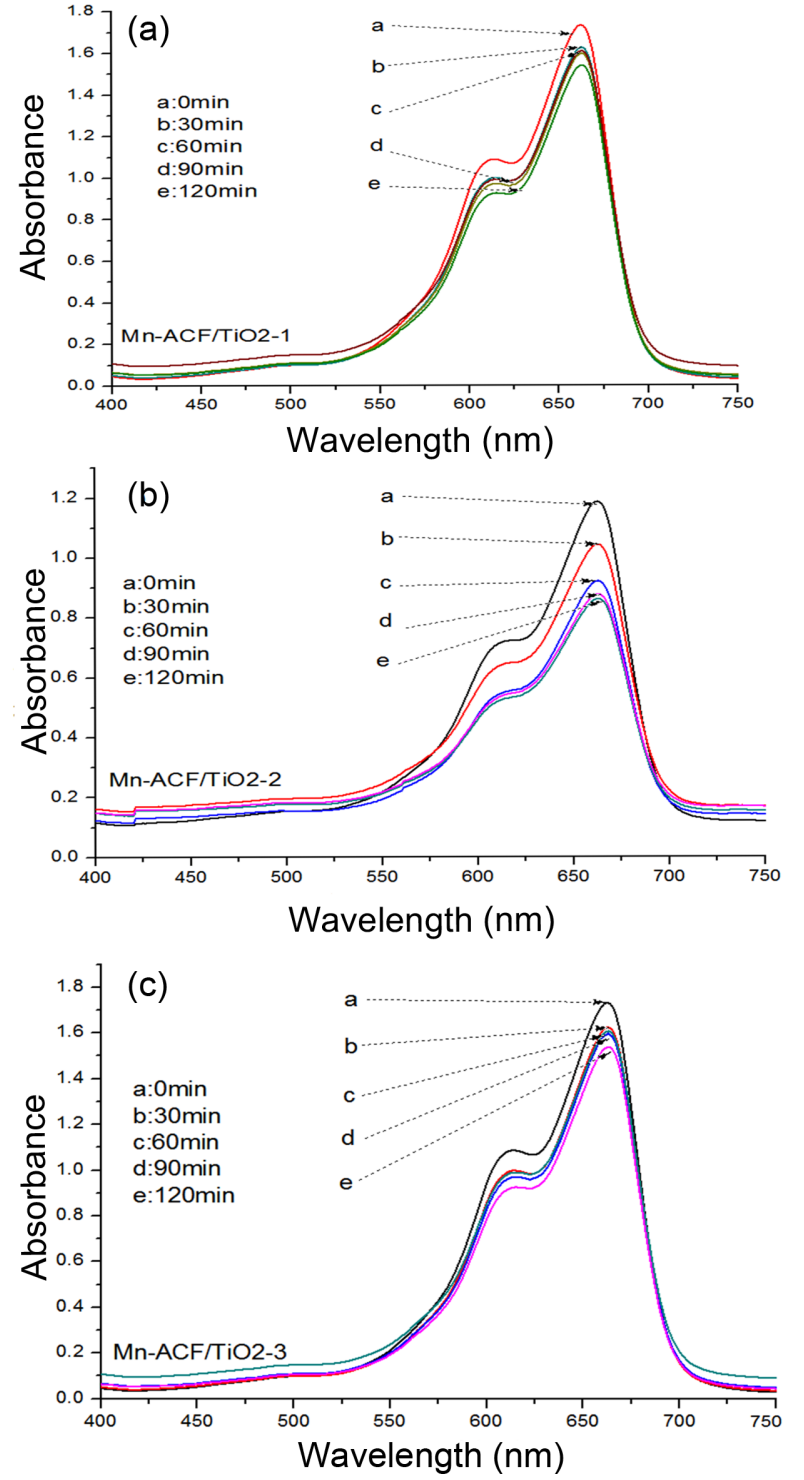

Fig. 3. UV/vis spectra of $\mathrm{MB}$ concentration against the Mn$\mathrm{ACF} / \mathrm{TiO}_{2}$ composite under various time conditions; $\mathrm{Mn}-\mathrm{ACF} / \mathrm{TiO}_{2}-1$ (a), Mn-ACF/TiO $2-2$ (b) and Mn-ACF/ $\mathrm{TiO}_{2}-3$ (c), respectively.

ation (Fig. 5). The absorbance spectral lines clearly indicate the gradual, significant and steady decrease in the absorbance with each passing time interval of $30 \mathrm{~min}$ for the MO solution. The maximum absorbance peak $\lambda_{\max }$ for MO was observed to be at $462 \mathrm{~nm}$. The degradation of $\mathrm{MO}$ at the $\lambda_{\max }$ wavelength was calculated and found to be $35 \%$ by the end of $120 \mathrm{~min}$ of exposure. It is obvious that $\mathrm{Mn}-\mathrm{ACF} / \mathrm{TiO}_{2}-2$ also has a high photocatalytic effect against MO dye. In previous research, ${ }^{26-27)}$ it was concluded that the decrease in absorbance for an organic dye should be attributed to a degradation reaction by certain kinds of carbon and $\mathrm{TiO}_{2}$ composite photocatalysts.

In order to further demonstrate the photostability and

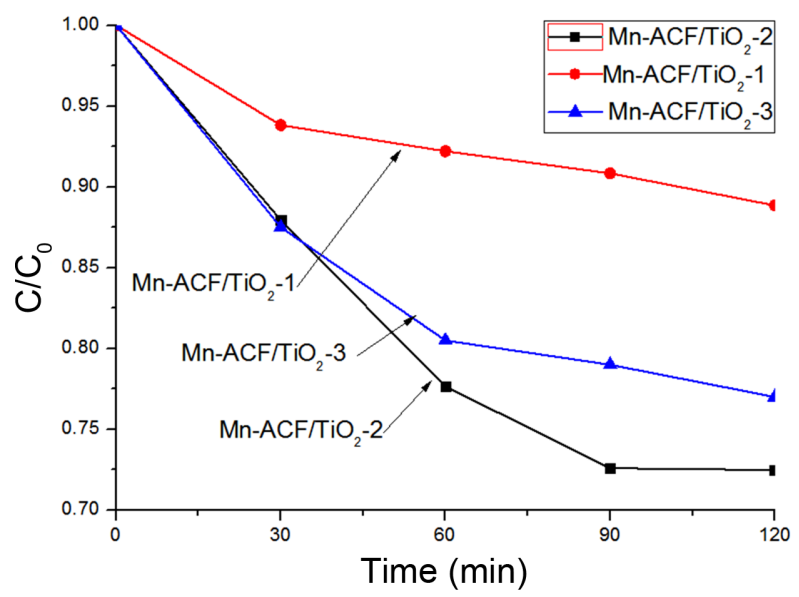

Fig. 4. Degradation of $\mathrm{MB}$ under visible light irradiation with magnetic stirring over $\mathrm{Mn}-\mathrm{ACF} / \mathrm{TiO}_{2}-1$, Mn$\mathrm{ACF} / \mathrm{TiO}_{2}-2$ and $\mathrm{Mn}-\mathrm{ACF} / \mathrm{TiO}_{2}-3$. c is the concentration of $\mathrm{MB}$ solution, and $\mathrm{c} 0$ is the initial concentration.

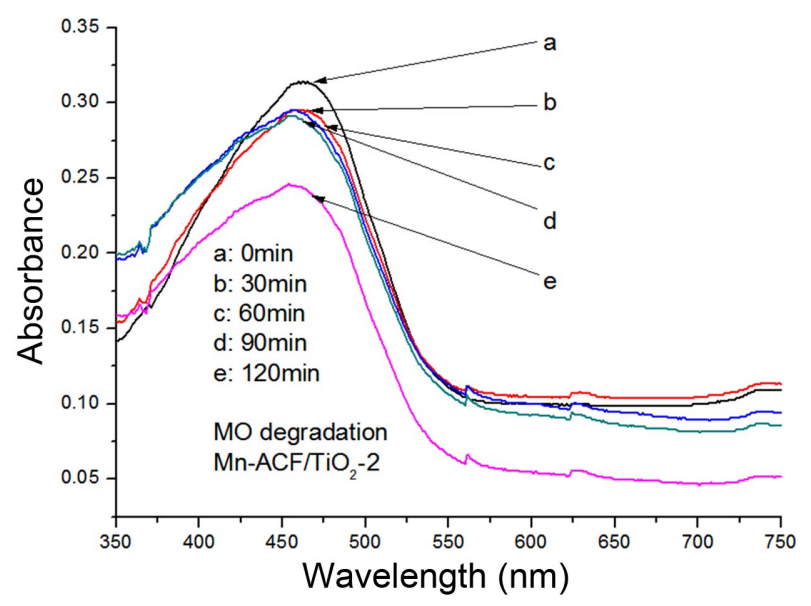

Fig. 5. UV/vis spectra of MO concentration against the Mn$\mathrm{ACF} / \mathrm{TiO}_{2}-2$ sample under visible light irradiation.

cycle performance of the $\mathrm{Mn}-\mathrm{ACF} / \mathrm{TiO}_{2}$ samples, circulating runs in the photocatalytic degradation of $\mathrm{MB}$ in the presence of $\mathrm{Mn}-\mathrm{ACF} / \mathrm{TiO}_{2}-2$ under visible light were conducted. As shown in Fig. 6, the photocatalyst did not exhibit any significant loss of photocatalytic activity after 3 runs of $\mathrm{MB}$ degradation, which indicates that the $\mathrm{Mn}-\mathrm{ACF} / \mathrm{TiO}_{2}-2$ photocatalyst had high stability and cannot be photocorroded during the photocatalytic oxidation of the MB solution. Thus, the Mn-ACF/TiO 2 -2 composite photocatalyst is promising for practical applications in environmental purification. This Mn-ACF composite can improve not only the photocatalytic performance of $\mathrm{TiO}_{2}$ but also the long-term stability of the $\mathrm{TiO}_{2}$ nanocrystals. These results are significant from the viewpoint of practical application because enhanced photocatalytic activity and prevention of catalyst deactivation will lead to a more cost-effective operation. ${ }^{28-30}$ ) 


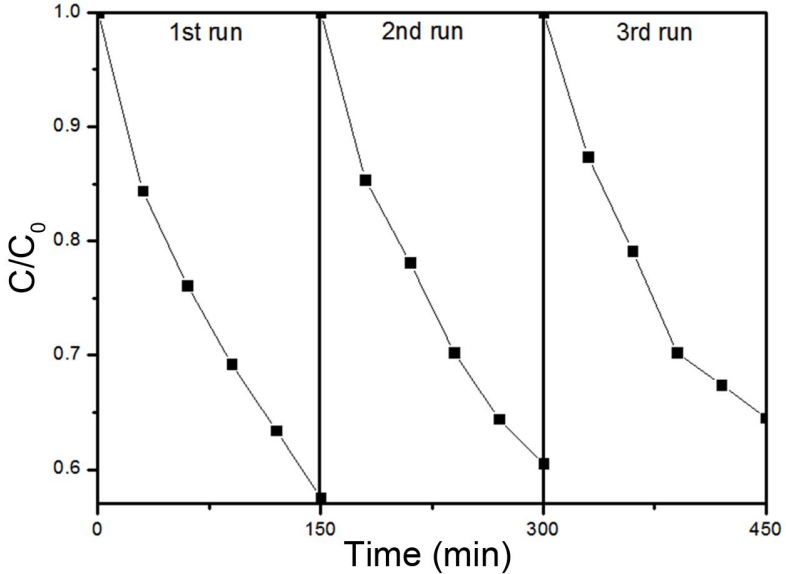

Fig. 6. Cycling runs for the photocatalytic degradation of $\mathrm{MB}$ with $\mathrm{Mn}-\mathrm{ACF} / \mathrm{TiO}_{2}-2$ sample under visible light irradiation.

\section{Conclusions}

In the characterization of $\mathrm{Mn}-\mathrm{ACF} / \mathrm{TiO}_{2}$ composites prepared from Mn-ACF and TNB, the adsorption and surface properties, and the structural and chemical composition were investigated through synthesis of the $\mathrm{Mn}-\mathrm{ACF} / \mathrm{TiO}_{2}$ composite. The X-ray diffraction patterns varied with strong peaks of anatase and $\mathrm{Mn}$ phase for the $\mathrm{Mn}-\mathrm{ACF} / \mathrm{TiO}_{2}$ composite. The EDX spectra showed the presence of major elements of $\mathrm{C}, \mathrm{O}$, and $\mathrm{Mn}$, with strong Ti peaks. The surface properties were confirmed in SEM images of the texture on the $\mathrm{Mn}-\mathrm{ACF} / \mathrm{TiO}_{2}$ composite. Finally, the photo-degradation of organic dye by $\mathrm{Mn}-\mathrm{AC} / \mathrm{TiO}_{2}-2$ shows excellent photocatalytic effects and high stability.

\section{REFERENCES}

1. J. P. Zhao, S. P. Pei, W. C. Ren, L. B. Gao, and H. M. Cheng, "Efficient Preparation of Large-Area Graphene Oxide Sheets for Transparent Conductive Films," ACS Nano., 4 [9] 5245-52 (2010).

2. A. Kasry, M. A. Kuroda, G. J. Martyna, G. S. Tulevski, and A. A. Bol, "Chemical Doping of Large-Area Stacked Graphene Films for Use as Transparent, Conducting Electrodes," ACS Nano., 4 [7] 3839-44 (2010).

3. L. G. D. Arco, Y. Zhang, C. W. Schlenker, K. M. Ryu, M. E. Thompson, and C. W. Zhou, "Continuous, Highly Flexible, and Transparent Graphene Films by Chemical Vapor Deposition for Organic Photovoltaics," ACS Nano., 4 [5] 2865-73 (2010).

4. R. Gover, P. Burns, A. Bryan, M. Saidi, J. Swoyer, and J. Barker, "LiVPO 4 F: A New Active Material for Safe Lithium-Ion Batteries," Solid State Ionics, 177 [26] 2635-38 (2006).

5. J. Li, A. Bao, and G. Mo, "Effect of Multi-Walled Carbon Nanotubes on the Electrochemical Performance of LiV$\mathrm{PO}_{4} \mathrm{~F}$ Cathode Material for Rechargeable Lithium-Ion
Batteries," Solid State Ionics, 264 45-8 (2014).

6. P. F. Xiao, M. O. Lai, and L. Lu., "Transport and Electrochemical Properties of High Potential Tavorite $\mathrm{LiVPO}_{4} \mathrm{~F}$," Solid State Ionics, 242 10-9 (2013).

7. L. Wu, S.-K. Zhong, J.-Q. Liu, F. Lv, and K. Wan, "High Tap-Density and High Performance $\mathrm{LiFePO}_{4} / \mathrm{C}$ Cathode Material Synthesized by the Combined Sol Spray-Drying and Liquid Nitrogen Quenching Method," Mater. Lett., 89 32-5(2012).

8. J.-C. Zheng, X.-H. Li, Z.-X. Wang, H.-J. Guo, Q.-Y. Hu, and W.-J. Peng, "Li3V $2\left(\mathrm{PO}_{4}\right)_{3}$ Cathode Material Synthesized by Chemical Reduction and Lithiation Method," J. Power Sources, 189 [1] 476-79 (2009).

9. F. Chen, P. Fang, Z. Liu, Y. Gao, Y. Liu, Y. Dai, H. Luo, and J. Feng, "Dimensionality-Dependent Photocatalytic Activity of $\mathrm{TiO}_{2}$-based Nanostructures: Nanosheets with a Superior Catalytic Property," J. Mater. Sci., 48 [15] 5171-79 (2013).

10. J. Jitputti, T. Rattanavoravipa, S. Chuangchote, S. Pavasupree, Y. Suzuki, and S. Yoshikawa, "Low Temperature Hydrothermal Synthesis of Monodispersed Flower-like Titanate Nanosheets," Catal. Commun., 10 [4] 378-82 (2009).

11. C. Berger, Z. Song, T. Li, X. Li, A. Y. Ogbazghi, R. Feng, Z. Dai, A. N. Marchenkov, E. H. Conrad, P. N. First, and W. A. de Heer, "Ultrathin Epitaxial Graphite: 2d Electron Gas Properties and a Route toward Graphenebased Nanoelectronics," J. Phys. Chem. B, 108 [52] 19912-16 (2004).

12. H. Gwon, H.-S. Kim, K. U. Lee, D.-H. Seo, Y. C. Park, Y.-S. Lee, B. T. Ahn, and K. Kang, "Flexible Energy Storage Devices Based on Graphene Paper," Energy Environ. Sci., 4 [4] 1277-83 (2011).

13. Z. Liu, Q. Liu, Y. Huang, Y. Ma, S. Yin, X. Zhang, W. Sun, and Y. Chen, "Organic Photovoltaic Devices Based on a Novel Acceptor Material: Graphene," Adv. Mater., 20 [20] 3924-30 (2008).

14. M. Huang, Y. Wu, and W. Hu, "A Facile Synthesis of Reduced Graphene Oxide-Wrapped $\mathrm{WO}_{3}$ Nanowire Composite and its Enhanced Electrochemical Catalysis Properties," Ceram. Int., 40 [5] 7219-25 (2014).

15. Y. Sun, Q. Wu, and G. Shi, "Graphene Based New Energy Materials," Energy Environ. Sci., 4 [4] 1113-32 (2011).

16. Q. Xiang, J. Yu, and M. Jaroniec, "Graphene-Based Semiconductor Photocatalysts," Chem. Soc. Rev., 41 [2] 782-96 (2012).

17. W. Han, L. Ren, L. Gong, X. Qi, Y. Liu, L. Yang, X. Wei, and J. Zhong, "Self-Assembled Three-Dimensional GrapheneBased Aerogel with Embedded Multifarious Functional Nanoparticles and its Excellent Photoelectrochemical Activities," ACS Sustainable Chem. Eng., 2 [4] 741-48 (2013).

18. Y. Zhang and C. Pan, " $\mathrm{TiO}_{2} /$ Graphene Composite from Thermal Reaction of Graphene Oxide and its Photocatalytic Activity in Visible Light," J. Mater. Sci., 46 [8] 2622-26 (2011).

19. Y. Aman, V. Garnier, and E. Djurado, "Spark Plasma Sintering Kinetics of Pure a-Alumina," J. Am. Ceram. Soc., 94 [9] 2825-33 (2011).

20. Y. Zhou, K. Hirao, Y. Yamauchi, and S. Kanzaki, "Densification and Grain Growth in Pulse Electric Current 
Sintering of Alumina,” J. Eur. Ceram. Soc., 24 [12] 3465-70 (2004).

21. X. Sun, Y. Xu, M. Jia, P. Ding, Y. Liu, and K. Chen, "High Performance $\mathrm{LiV}_{0.96} \mathrm{Mn}_{0.04} \mathrm{PO}_{4} \mathrm{~F} / \mathrm{C}$ Cathodes for Lithium-Ion Batteries," J. Mater. Chem. A, 1 [7] 2501-7 (2013).

22. J. Zheng, B. Zhang, and Z. Yang, "Novel Synthesis of LiV$\mathrm{PO}_{4} \mathrm{~F}$ Cathode Material by Chemical Lithiation and Postannealing," J. Power Sources, 202 380-83 (2012).

23. N. Murayama and W. Shin, "Effect of Rapid Heating on Densification and Grain Growth in Hot Pressed Alumina," J. Ceram. Soc. Jpn., 108 [1261] 799-802 (2000).

24. Y. Aman, V. Garnier, and E. Djurado, "A Screening Design Approach for the Understanding of Spark Plasma Sintering Parameters: A Case of Translucent Polycrystalline Undoped Alumina," Int. J. Appl. Ceram. Technol., 7 [5] 574-86 (2010).

25. X. Feng, Z. Yan, N. Chen, Y. Zhang, Y. Ma, X. Liu, Q. Fan, L. Wang, and W. Huang, "The Synthesis of ShapeControlled $\mathrm{MnO}_{2} /$ Graphene Composites via a Facile OneStep Hydrothermal Method and their Application in Supercapacitors," J. Mater. Chem. A, 1 [41] 12818 (2013).
26. J. Cao, Y. Wang, Y. Zhou, J.-H. Ouyang, D. Jia, and L. Guo, "High Voltage Asymmetric Supercapacitor Based on $\mathrm{MnO}_{2}$ and Graphene Electrodes," J. Electroanal. Chem., 689 2016 (2013)

27. X. Rong, F. Qiu, C. Zhang, L. Fu, Y. Wang, and D. Yang, "Preparation, Characterization and Photocatalytic Application of $\mathrm{TiO}_{2}-$ Graphene Photocatalyst under Visible Light Irradiation," Ceram. Int., 41 [2] 2502-11 (2015).

28. M. Kim, M. Yoo, Y. Yoo, and J. Kim, "Microelectronics Reliability Capacitance Behavior of Composites for Supercapacitor Applications Prepared with Different Durations of Graphene/Nanoneedle $\mathrm{MnO}_{2}$ Reduction," Microelectron. Reliab., 54 [3] 587-94 (2015).

29. S. Deng, D. Sun, C. Wu, H. Wang, J. Liu, Y. Sun, and H. Yan, "Synthesis and Electrochemical Properties of $\mathrm{MnO}_{2}$ Nanorods/Graphene Composites for Supercapacitor Applications," Electrochim. Acta., 111 707-12 (2013).

30. A. Martín and A. Escarpa, "Graphene: The Cutting-Edge Interaction between Chemistry and Electrochemistry," TrAC Trends Anal. Chem., 56 13-26 (2014). 